\title{
Selective Secondary School Education In Barbados: The Need For Change
}

\author{
Marcia Pilgrim \\ Providence Secondary School \\ Garry Hornby a \\ University of Plymouth \\ Tara Inniss \\ University of the West Indies
}

\begin{abstract}
This article examines the implications of selective secondary school education in Barbados for the provision of an inclusive and equitable education system and highlights its impact on educational outcomes. The concepts of inclusion and equity in education are discussed and their importance in achieving the education goals of nations within the Englishspeaking Caribbean are highlighted. The historical development of the selective secondary school system in Barbados is outlined and the inequity perpetuated by high stakes selection examinations are examined. The ongoing effects of the ability grouping that result from this process are discussed. The need for a move away from a selective secondary education system is proposed and a possible means for bringing about this change in Barbados is explored. This has important implications for countries in the Caribbean and in other parts of the world that have selective secondary school education systems.
\end{abstract}

Keywords: equity, inclusion, selective education, ability grouping, education systems

\section{Introduction}

Selective secondary schooling in Barbados has implications for educational outcomes, the social inclusion of all children, and the provision of an equitable education system. The concept of social inclusion is used as a lens through which to view practices aimed at including individuals and groups living at the margins of society as a result of poverty or other forms of disadvantage. As such it is embedded in the values of an equitable and just society (Terzi, 2014). Inclusive education is regarded as an important vehicle through which a socially inclusive society might be achieved (UNESCO, 2000) and, it is argued, "...places the well-being and agency of all children, and children with disabilities and difficulties in particular, at the centre of the educational process" (Terzi 2014, p. 480).

\section{Inclusion and Equity}

The inclusive agenda in education recognizes the rights of all students to a quality education, so is by its very nature an equity agenda. It is promoted through education systems that support all students in reaching their full potential, "...without either formally or informally erecting barriers or lowering expectations" (Schleicher 2014, p. 19). Internationally, inclusion and equity are regarded as essential to the creation of the highly skilled work forces needed to drive the economic growth of nations and promote their social cohesion (Schleicher, 2014, 2018). These concepts underpin the Barbados Human Resource Development Strategy 2011-2016, with its mission statement, "To

Correspondence can be directed to: garry.hornby@plymouth.ac.uk 
develop national, institutional, and human capacity so that the potential of all Barbadians is fully realized" (Ministry of Education and Human Resource Development 2010, p.1).

The concepts of inclusion and equity are also echoed in national policy documents across the English-speaking Caribbean. For example, the National Strategic Plan of the Republic of Trinidad and Tobago, Vision 2020, aims to ensure that diversity is valued, citizens benefit from a relevant education system, and that every citizen has an equal opportunity to achieve his or her full potential. In addition, the promotion of inclusive education is identified as an important component in achieving quality education outcomes (Ministry of Planning and Development, nd). Similarly, in the document, The Development of Education, the Ministry of Education in Jamaica outlines its commitment to promoting inclusive education, and emphasis is placed on the need to ensure equal opportunities for all students irrespective of their cultural, economic and social status or their perceived abilities or disabilities (Ministry of Education, Jamaica, 2008).

As is the case with other Caribbean nations, Barbados has embraced a range of international agreements as part of its aim to promote equitable and inclusive education and to improve educational outcomes for students. These include a commitment to Education for All goals (UNESCO, 1990) that were adopted by the World Conference on Education for All in Jomtien, Thailand in 1990. Against an international backdrop of great inequity in which over 100 million children, including at least 60 million girls, were without access to primary education, one of the stated purposes of the Education for All goals was to promote equity and reduce disparities in education. Within its broad vision of including all marginalized groups, it was recognised that, "the needs of the disabled demand special attention" (UNESCO 2000, p.75).

Based on an evaluation of progress towards the 1990 goals, Barbados was one of the nations that recommitted itself to the vision of Education for All by adopting the Dakar Framework for Action (UNESCO, 2000). A major focus for many large states remained universal access to basic education and the increase of educational opportunities for girls (Crossley, Bray and Packer, 2011). However, like many small island states able to take advantage of their small scale, educational priorities in Barbados have moved beyond these parameters and lay instead in focusing on improving the quality of education (Crossley and Sprague, 2012; Rudder, 2014). To this end, improving educational opportunities in ways that are equitable and inclusive and do not discriminate or exclude vulnerable groups, for example, the poor and those with special educational needs and disabilities, remains an important imperative (UNESCO, 2000).

Central to the concept of equity in education is the understanding that all learners are of equal importance (De Lisle, 2012; Shaeffer, 2013; UNESCO, 2017). For equity to be achieved the personal circumstances of young people, for example, socio-economic status, gender and ethnicity, must not be obstacles to their educational success. The equity agenda is regarded not only as a social justice imperative but also as a way of ensuring that resources are used effectively in the pursuit of national prosperity (OECD, 2016). Schleicher (2014) emphasises that where optimum opportunities are available for all members of a society to develop skills and achieve success in the educational process, they are likely to participate more fully in economic, social, civic and political processes. They are also less likely to be a burden to society in terms of health costs and involvement in crime. It is critical therefore that all nations, including small island developing states, such as those in the Caribbean, reflect on the capacity of their educational systems to promote equity.

The education of its people has been a national priority for successive governments of Barbados. Consequently, Barbadians have enjoyed the benefits of universal access to primary and secondary education for many years through an extensive network of schools (Ministry of Education, Youth Affairs and Culture, 2000). The high priority given to education is demonstrated by the large financial commitment to the sector. On average $16 \%$ of government spending in Barbados and $6 \%$ of Gross Domestic Product (GDP) has been allocated to education over the past thirty years (Rudder, 2014). Of the three independent Caribbean Community countries considered to be the most developed, including Jamaica and Trinidad and Tobago, Barbados has invested the most heavily in education (Jennings, 2017). 
Indeed, several initiatives aimed at improving the quality of education, and thereby outcomes for students, have been undertaken in recent years as a result of this significant investment and a range of achievements have been reported (Rudder, 2014). For example, high literacy rates being maintained and renewed emphasis placed on teacher training. Emphasis has also been placed on professional development, for example, through the implementation of a positive behaviour management programme that has seen training in all nursery, primary and secondary schools. In addition, early childhood education provision has been expanded, information technology has been better integrated into the school system and continued opportunities for young people to pursue technical and vocational training and to acquire work related skills have been provided (Rudder, 2014). Barbados has also pursued initiatives aimed specifically at advancing its special and inclusive education agenda and seeks to provide a continuum of options for students with special educational needs, from full-time placements in special schools, through to pull-out support in resources centres, as well as access to full inclusion models where students remain in the regular classroom for all of their time at school (Blackman, Conrad and Brown, 2012).

Despite progress made towards Education For All goals, ensuring the quality of the education system and improving educational outcomes for young people remains a concern in Barbados (Rudder, 2014). In order to gain a better understanding of how the education system might be improved so that student outcomes are optimized, it is important to address issues that may give rise to hidden but systemic inequity and therefore have an impact on the realization of optimum student outcomes nationally. In seeking to understand these issues, the historical context and legacy of the education system in Barbados, and in other counties of the English-speaking Caribbean, must be considered.

\section{Historical Context}

The education system in Barbados has its roots in the plantation slave-based society that characterized most of the colonial period. During this period, wealthy planters who were resident on the island sent their children, mostly sons, to be educated in Britain, while daughters had a limited education, sometimes acquired through small local private schools, which focused on their roles as wives and mothers to the elite planter class (Mayers, 1995). Education of the enslaved population was not encouraged and there were limited opportunities for poor whites. However, as early as 1682, wealthy planters identified the need to provide some level of education, especially for poor white boys, and a number of legacies were entrusted to establish schools, such as The Lodge School, Harrison College, Combermere and Queen's College, which still exist today (Bacchus, 2006). Eventually these schools developed enviable academic reputations, becoming the preferred institutions on the island to send promising children of both elite and non-elite backgrounds.

However, educational opportunities for the enslaved population throughout this period were minimal and, with some exceptions, there was an active attempt by the wealthy elite to limit their education. For example, from the 1660s, the Quakers promoted Christian education of their enslaved workers but were persecuted to the point of exile for such anti-slavery sentiments. Only at the Codrington Estates did enslaved workers and their children receive rudimentary Christian instruction (Bennett, 1958). Following the incursion of Christian missionaries such as the Moravians and Methodists, Christian education spread to a number of other estates. However, it was not until 1818 that the first school for enslaved and free coloured children was established in Bridgetown (Blouet, 1991). As slave emancipation became imminent in the early nineteenth century, the Anglican Church took an increasing interest in providing education as a means of instructing a newly emancipated population in the responsibilities of freedom and Christian morality, in order to maintain economic, political and social order in the society. Many of the primary and secondary schools that evolved have now been incorporated into the public education system. It is clear, therefore, that the Barbadian education system is rooted in inherited inequalities that have subsequently proven challenging to shed. 
Prior to independence, colonial educational systems in the English-speaking Caribbean continued to be elitist and to serve the purpose of reinforcing economic and social hierarchies in Caribbean societies, which kept the working classes on the bottom while only allowing for the selected elevation of a small number of high-achieving students to elite gender-segregated secondary schools (Best, 2008). It was thought that this elite group, mostly boys, would benefit from the academic secondary education provided and would fill posts in the civil service, with some going further to gain university entrance and form the intellectual and professional elite of the colonies. Girls' education was often limited to gendered stereotypes of women's domestic roles as wives and mothers, with promising female students only being encouraged to enter the nursing and teaching professions (Downes, 2003). In a context in which there were very few secondary school places available, those students seeking admission underwent a competitive selection process by way of various secondary school entrance examinations. It is on this legacy of selection of the few that the post-colonial education system in the English-speaking Caribbean was built. It is a legacy that has endured, despite the expansion of secondary school systems across the Caribbean to achieve the realization of universal secondary education (De Lisle, 2012; De Lisle, Seecharan and Ayodike, 2010).

In Barbados, each secondary school had its own entrance examination. But in 1959, there was the introduction of what is today known as the Barbados Secondary Schools Entrance Examination (BSSEE), or the Common Entrance Examination (CEE), which was a standard test for students between the ages of 10 and 12 to be allocated a place in a secondary school. This was considered to be needed since, during the post-independence era, from the late 1960s, secondary education continued to be highly valued by the general population at a time when there were not enough places to meet the growing demand. Therefore, secondary school entrance examinations were widely viewed as a fair way to select those students considered most deserving of the limited places. The stakes in these examinations were high, as future life chances and opportunities for social mobility and economic success were closely linked to success or failure on the examination (De Lisle, 2012; De Lisle et al., 2012).

By the start of the $21^{\text {st }}$ Century, universal access to secondary education had been put in place in many Caribbean countries. However, high stakes examinations at the transition between primary and secondary school remained a prominent feature of the educational landscape, even though many territories had by that time committed enough secondary school places for every student in the compulsory education system, and mostly within close proximity to students' homes (DeLisle, 2012). Although test names and content have undergone some changes, their role simply changed from being a mechanism for awarding the few coveted places to the most deserving, to one of channeling the best students into the most prestigious and highly sought-after schools. Therefore, a key legacy of the colonial era, that has remained in place across the Caribbean, is a selective system that is stratified, segregated, elitist and exclusionary (De Lisle, 2012). In Barbados this system has been successful in producing a small number of highly educated young people at the expense of providing a less than exemplary education for the majority of secondary school students. This is illustrated by results of the annual award of prestigious scholarships for university study to a few dozen students when they complete secondary education. The winners of these scholarships come almost exclusively from the two highest ranked of the 24 government secondary schools, Harrison College and Queens College (Downes, 2018), whereas the majority of prison inmates come from the eight lowest ranked secondary schools (CJRPU, 2017).

In order to explain the impact of this historical legacy the following section will discuss the use of high stakes education placement tests in the English-speaking Caribbean. The intentions as well as the consequences of such tests will be considered. Issues relevant to segregation within the secondary school system will be discussed and consideration given as to whether such a system serves to perpetuate inequity and further disadvantage vulnerable groups in society, including students with special educational needs and disabilities. 


\section{High Stakes Placement Tests in the Caribbean}

High stakes tests are considered to be, "...any tests the results of which are used to make important decisions about students, educators, schools, or districts" (Glossary of Education Reform, 2014). After independence, tests at the end of primary education for the purpose of placing students into different secondary schools continued to be administered in English-speaking Caribbean countries, with high stakes for students and their families. Countries in which such tests are a central feature of the education system include St. Lucia, St. Vincent and the Grenadines, Grenada, Jamaica, Barbados, Belize, Guyana, and Trinidad and Tobago. Tests vary in name and content between countries but typically cover similar curriculum areas such as Language, Creative Writing and Mathematics (De Lisle, Smith, Keller and Jules, 2012). For example, in Trinidad and Tobago the national selection examination is the Secondary Entrance Assessment (SEA), while in Barbados the Common Entrance Examination (CEE) is administered, and in Jamaica the results of the Grade Six Achievement Test (GSAT) are used for placing students in secondary schools (De Lisle et al 2012; Jennings, 2017; Ministry of Education, Youth Affairs \& Culture, 2000; Jamaica Task Force on Educational Reform, 2004).

When considering the use of these tests, it is important to understand their educational intentions as well as their consequences for young people and the societies that they serve. High stakes tests are intended to serve important policy goals, for example, to raise student achievement levels and ensure equal opportunity. The rationale for their use is that allocating students to supposedly homogeneous groups allows teachers to focus teaching of the curriculum more carefully on the needs and aptitudes of students and to teach at a pace that will enable all students to maximize their learning (De Lisle et al 2012; Jennings, 2017). Advocates of this type of grouping consider, for example, that in homogeneous groups more able students are less likely to become disengaged because of a slow pace of learning while less able students will benefit from a pace of learning better suited to their needs (Hanushek and Woessmann, 2005).

However well intentioned high stakes placement tests are, it must be recognized that the use of such tests to separate students into schools or classes of different ability levels is not supported by research evidence of improved education outcomes (Slavin, 1990, 1993). Instead, research suggests that where students are allocated places in schools based on ability or attainment, school systems become segregated by social-economic status and educational outcomes are inequitable (Gorard and Huat See, 2013). Decisions to implement high stakes placement tests can, therefore, have far reaching negative consequences for young people and societies, as well as running counter to the values of inclusive education, which seeks to welcome and embrace diversity in all schools.

Gorard and Huat See (2013) refer to segregation in the school system as the clustering of students with certain characteristics into schools with others like themselves. In implementing a testing regime to feed such a system it is critical to carefully weigh its potential benefits against its probable negative consequences in order to determine whether the testing regime achieves better overall educational outcomes for students and also to evaluate its impact on equity within the education system.

\section{Inequity and Common Entrance Examinations in the English-Speaking Caribbean}

One of the stated intentions of high stakes examinations in the English-speaking Caribbean is to, "allocate places in the secondary school fairly" (De Lisle et al. 2012, p.59). In its White Paper on Education Reform in Barbados, the Ministry of Education, Youth Affairs and Culture (1995) concludes that the CEE should be retained in Barbados at the transition between primary and secondary school because it is perceived as the fairest means of assessing students. However, research (De Lisle et al., 2012) suggests that the extent to which the goal of fairness is achieved is questionable and therefore the decision to continue to use this test based on a perception of fairness must be carefully scrutinized. In evaluating evidence from Secondary Entrance Assessment (SEA) data in Trinidad and Tobago between 1995 and 2005, De Lisle et al. (2012) noted that results suggested complex patterns of gender disadvantage as well as disadvantages related to socio-economic status and ethnicity. 
In Trinidad and Tobago, as in other Caribbean countries including Barbados, an element of parental choice forms part of secondary school placement. Parents indicate which schools they would like their children to attend. If, however, their children do not achieve the marks on the SEA or CEE required for eligibility to the schools chosen by parents, they will not be admitted to those schools and will instead be assigned to other schools. The De Lisle et al. (2012) study found that students living in high-income areas were far more likely to gain entry into schools of their choice, whereas students from low-income areas were not. In addition to these concerns that children from poorer backgrounds were being disadvantaged, the authors also point to other issues relevant to achieving fairness in high stakes testing. Attention is drawn to how actual test design has the potential to disadvantage some groups of learners more than others. For example, following a 2005 redesign of the SEA in Trinidad and Tobago, results indicated that a greater proportion of boys were falling below the $30 \%$ cut off score and therefore increasing numbers of boys were being identified as having special educational needs and being allocated to remedial placements. Findings such as these highlight concerns that tests such as the SEA or CEE are not the neutral tools for allocating places fairly that they are perceived to be by the public in Caribbean countries.

Although there are only a small number of studies related to placement tests in the Caribbean, from the 1960s onwards researchers such as Cross and Schwartzbaum (1969), in their analysis of the impact of SEA data, pointed to its segregating effect in Trinidad and Tobago. Students were found to be entering secondary schools divided along lines that reflected their socio-economic status and ethnicity. Jules (1994) in his study of data collected between 1986 and 1993 also found that groups of students experienced disadvantage due to factors such as socio-economic status, ethnicity and gender. Additionally, in Barbados, a report on the transfer of students from primary to secondary schools found that students were advantaged or disadvantaged depending on the quality of the primary school they attended (Barbados Ministry of Education, 1974). It was also found that children who were economically advantaged and attended private primary schools were far more likely to gain entry into elite secondary schools. For example, Jennings (2017) reports on statistics that indicate that $64 \%$ of children who attended a private primary school in Barbados were likely to perform above the national average in the English component of the CEE, compared with only $11 \%$ of those who attended government primary schools.

To summarize, the perceptions of Caribbean communities that by using tests such as the SEA or CEE fairness is achieved is not borne out by the evidence to date. On the contrary, evidence suggests that attempts at academic segregation at the transition to secondary schools in the Caribbean result in inequity characterized by the clustering of socio-economically advantaged students into the most prestigious schools. Such an effect is incompatible with the aims of inclusive education as a vehicle for equity and social justice and with the current vision of an inclusive education system, as outlined in government policy documents (Ministry of Education and Human Resource Development, and Ministry of Labour, 2010; Ministry of Planning and Development, nd).

\section{Other Unintended Consequences Associated with High Stakes Examination}

Apart from the negative effects discussed above, a range of other unintended consequences of high stakes tests have been identified in the literature. These relate to the overwhelming pressure of these tests on teachers, schools and parents, in addition to their impact on students socially and academically (Galloway and Upton, 1990; Walker and Musti-Rao, 2016).

A key issue is the narrowing of the curriculum, and the use of teacher-centred rather that student-centred pedagogy, as a result of the focus of primary school teachers and schools on safeguarding their reputations by achieving examination success in the CEE (Jennings, 2017). Such a focus leads to the neglect of important curriculum areas not prioritized by the CEE, for example, higher order thinking skills and other critical skills such as the ability to work as a part of a team to co-create knowledge in online as well as face-to-face contexts (Best, 2008; De Lisle, Laptiste-Francis, McMillan-Solomon and Bowrin-Williams, 2017; Klenowski and Wyatt-Smith, 2012). 
Concerns about the impact of the CEE on primary school teaching and curricula have long been acknowledged (Carrington, 1993; De Lisle et al, 2017; Galloway and Upton, 1990). At the same time the increased attention paid to those students most likely to succeed in the examination, as well as the teacher-centred rather than student-centred approaches commonly pursued in order to achieve good examination results, is likely to be to the detriment of students with learning difficulties, who benefit from programs and approaches that are more tailored to meet their needs. This is likely to exacerbate patterns of disadvantage and exclusion rather than promote the inclusion of students with special educational needs (De Lisle et al, 2012; Walker and Musti-Rao, 2016). Such unintended consequences have been identified in other stratified education systems such as that in Singapore, as noted by Walker and Musti-Rao (2016, p.16).

Although mainstream teachers are encouraged and willing to support students with special needs in classes, the emphasis on covering curricular content in preparation for the national exams does not provide adequate support to students with special needs

Alongside the unintended consequences discussed above, in such examination driven education systems, a private tutoring industry typically flourishes (often referred to in Barbados as 'lessons'). These 'lessons' are more easily accessed by economically advantaged families, with children from impoverished families more likely to miss out, or their parents placed under further economic strain (Best, 2008; Jennings. 2017). This industry also presents ethical challenges in countries, such as Barbados, where teachers with responsibility for students as part of their daytime teaching roles are also legally permitted to provide private paid tutoring to those same students, and those from other schools, outside of school hours (Bray, 2013).

In view of ongoing concerns in the community about increasing levels of violence by students from some of the less prestigious secondary schools in Barbados, it is important to consider other possible unintended consequences of a highly stratified system, as opposed to a more inclusive and equitable system that helps to promote social cohesion (Schleicher, 2014, 2018). With many students being unable to attend their nearest school and having to travel to the schools in other parts of the island for which they have gained entry, large numbers of secondary students spend considerable lengths of time travelling to and from school each day. This often involves having to take buses to school and changing buses at least once on the way to school and then again on the way back home. Students may spend up to four hours a day travelling between home and school in hot conditions on buses that are not air-conditioned with inadequate supervision. As a result of this many students arrive at their secondary schools tired before they start classes and arrive home in the evening too exhausted to concentrate on homework.

The effects of the above situation are regularly reported in local newspapers when incidents of aggression and violence arise among students at school, or riding on the buses, or waiting at bus-stops or in bus terminals (Harrison 2018, p.10). Harrison's appeal to, "...eliminate the current allocation system of bussing academically weak students to particular schools which are far away from their homes", bears very serious consideration in the context of current literature and the experiences outlined above.

Furthermore, the negative consequences of the CEE have been recognized for many years by the Government of Barbados, which in its White Paper on Education Reform: Each One Matters... Quality Education for All, openly admits that,

The single summative test, such as the BSSEE, is associated with poor teaching, student misbehaviour, low motivation and fear, and thus "...exerts adverse effects on...(the) quality of education" (Ministry of Education, Youth Affairs and Culture 1995, p. 68). 


\section{Segregation within Secondary Schools - the Ongoing Impact}

Gorard and Huat See (2013) emphasize that damage is caused to educationally disadvantaged groups, including students from poor homes and those with special educational needs, within highly stratified and segregated systems, where these disadvantaged groups become clustered into less prestigious schools. They suggest that this damage may be the result of a range of factors, including the restricted exposure of disadvantaged students to a broad range of peers representative of society as a whole.

Buchmann and Dalton (2002) emphasize that it is in the secondary school context where important peer group relationships are formed. Drawing on evidence from a range of educational systems, these authors posit that, in highly differentiated systems, the influence of the peer group on student attitudes and aspirations is greater than the influence of parents and teachers. In schools that limit the range of peers to which students are exposed, the aspirations of students may also be limited, affecting their educational and occupational attainment (Buchmann and Dalton 2002). Gorard and Huat See (2013) concur that where disadvantage is clustered into particular schools, and students are not exposed to a school population representative of society, exposure to positive role models and information about future opportunities may be limited. In addition, Schleicher (2014) draws attention to the many opportunities for learning that are missed by lower ability peers in situations where they are excluded from interacting with higher ability students.

Societal perceptions are also impacted by school stratification, with implications for student self-perception. This is an issue noted by Carrington (1993) in his report summarizing policy issues and concerns identified in the Caribbean community. Schleicher (2014) points out that the clustering of high ability students into more prestigious schools contributes to the creation of stereotypical views of students and serves to stigmatize students attending less prestigious schools. Such stigmatization has a negative impact on student engagement, contributing to extensive underachievement in the school population (De Lisle, et al., 2012; Galloway and Upton, 1990; Gorard and Huat See, 2013). In addition, student engagement and attainment may also be influenced by institutional practices with lower ability students, who are more likely to be assigned less well qualified and less experienced teachers than their higher ability peers (Betts and Shkolnik, 2000; Kutnick, Blatchford, Galton, and Thorp, 2005). In light of the evidence pointing to the central role of the teacher in improving educational outcomes for students (Galloway \& Upton, 1990; Hattie, 2009), this is a major cause for concern.

Although the potential disadvantages of selective systems are many, such systems based on ability grouping practices are perpetuated without evidence of advantages for educational attainment (Gorard and Huat See, 2013). The following section will identify various forms of ability grouping within education systems generally and the Barbadian system specifically. The evidence for their use in promoting educational achievement will be evaluated.

\section{Ability Grouping}

Ability grouping is concerned with the way in which educational systems and schools organize instruction to meet the needs of diverse school populations (OECD, 2016). Ability grouping comprises streaming, setting and within-class grouping. While the term streaming is commonly used in Canada and the UK, this form of grouping is often referred to as tracking in the USA.

Streaming refers to the separation of students into particular groups based on their perceived overall ability. Although there are some limited opportunities for parental choice with regard to secondary school placement in Barbados, the CEE is in effect used as a national tool to stream students into a hierarchy of secondary schools. Students gaining the highest scores in the CEE are eligible for entry into the highest ranked and most prestigious schools, while those with the lowest scores are allocated to the lowest ranked and least prestigious schools. In addition, within those hierarchically based schools, further streaming of students into classes of different ability levels is also typically undertaken. 
Setting is a more nuanced approach to ability grouping and refers to the practice of having students in mixed ability classes for most of their schooling while placing them in groups for particular curriculum areas, dependent on their perceived ability in that particular curriculum area. This means, for example, that while a student may be in a top set for English, that same student may be in a bottom set for Mathematics and a middle set for Spanish. Within-class grouping is a more informal approach to grouping undertaken by teachers. Teachers may, for example, place students in groups within the classroom dependent on their ability within a curriculum area, or for other reasons, such as to utilize or encourage friendship groups. Mixed-ability grouping involves randomly assigning children to classes so that there is a similar spread of abilities in all classes at each age level. Therefore, mixed-ability classes include children considered to have low, average and high ability levels, as well as those with special educational needs and disabilities.

Whether ability grouping is utilized between schools, within schools or within classes, evidencebased criteria need to be used to examine its effectiveness in order to determine whether outcomes have been improved and an appropriate trade-off between efficacy and equity has been achieved (Hanushek and Woessmann, 2005). Where there is insufficient evidence to support its effectiveness, equity may be compromised for no advantage, in the face of numerous potential disadvantages (Gorard and Huat See, 2013).

Evidence about ability grouping has been provided by two large-scale systematic reviews and meta-analyses of research studies on ability grouping in schools, which have both found that there is little research evidence for its effectiveness in raising overall levels of educational achievement. In the largest of these reviews conducted to date, Hattie (2009) found that the effect size for the impact of ability grouping was well below the average for interventions in the field of education. Whereas, in the other large-scale review (Educational Endowment Foundation, nd) the Teaching and Learning Toolkit reported that it has a negative impact on overall educational achievement. Therefore, ability grouping is not a practice that is based on research evidence for its effectiveness in improving outcomes. However, schools in many countries around the world continue to use different forms of ability grouping, despite extensive research evidence which shows that such grouping is at best ineffective and at worst harmful to students (Slavin, 1987, 1990, 1993, 1996; Schleicher, 2018).

The most detrimental form of ability grouping is considered to be when education systems, such as Barbados, use between-school streaming, with an examination to assess 'ability' around eleven years of age determining what level or type of school students will attend from then on. This between-school streaming is still used in many countries around the world and is considered to produce a high level of academic achievement for a minority of students at the expense of underachievement for the majority of students (Gorard and See, 2013; Kutnick et. al 2005).

In contrast, many countries, such as New Zealand, use within-school between-class streaming from around eleven years of age, with students assigned to classes within schools designated as high, middle and low ability. This practice is widespread in New Zealand intermediate and secondary schools, despite schools acknowledging that there appears to be little benefit for most students, and that there are negative consequences including low self-esteem and behavioural difficulties for many students (Hornby and Witte, 2014; Hornby, Witte and Mitchell, 2011). In the case of many Caribbean countries, including Barbados, within class grouping and between-class streaming are widely used in primary schools, while between-school and between-class streaming are utilized at the secondary school level, thereby compounding the negative consequences of ability grouping (Galloway and Upton, 1990).

\section{The Need for Change}

Various stakeholders agree that, despite its achievements in the past, the education system in Barbados needs to undergo significant change if it is to better meet the needs of the nation in the $21^{\text {st }}$ Century (Best, 2008; Carrington, 1993; Rudder, 2014; World Bank, 2013). The system has been subject to scrutiny over many years with various reports identifying ongoing and systemic concerns. 
Carrington (1993) acknowledged that one frequently raised concern relates to the continued use of the CEE as a means of streaming students into schools. Carrington (1993) also draws attention to issues of inclusion in education and society that are inter-woven with the policies of stratification by perceived ability. He posits that education needs to play a role in helping to promote societal values and to change attitudes to students with difficulties and disabilities in the Caribbean community, and that all students should be nurtured in ways that encourages tolerance and supports them to value difference and develop positive attitudes towards their peers, whatever their difficulties or disabilities. Carrington (1993, p. 31) posits that, "Such attitudes and perceptions are best nurtured in situations where all children learn in the same environment." Promoting positive attitudes to diversity of ability and need underpins the guiding philosophy of Caribbean countries that seek to ensure that each student is valued in the education system (Ministry of Education, Human Resource and Development, 2008). These values are at the heart of the international drive to promote equity and inclusion in education.

\section{Systems that Foster Equity and High Levels of Attainment}

Although the challenge of achieving educational equity and optimal educational outcomes is international in scope it has long been recognized that the situation in each country is different and therefore there is no one recipe that can be followed in order to achieve these aims (Carnoy, 1999). Increasingly, however, international studies conducted by organizations such as Trends in International Mathematics and Science (TIMSS); Programme for International Student Assessment (PISA); and, Progress in International Reading Literacy Study (PIRLS) are providing useful insights into interventions that are linked to improvements in educational outcomes. Therefore, implications from the findings of these studies are being used by many countries around the world to bring about changes in their education systems (Ripley, 2013; Schleicher, 2014, 2018). For example, a key factor relevant to achieving equity for students that emerged from the 2012 PISA study is that, in countries that utilize selection of students at an early age, the impact of socio-economic status on educational performance is stronger than in countries that select at a later age (Budginaite et al 2016; OECD, 2016). This indicates that later selection is related to more equitable and higher achieving education systems.

One country that has invested extensively in overhauling its education system is Finland, now internationally considered to be one of the most equitable and highest performing education systems in the world. Indeed Finland provides an example of a comprehensive, rather than selective, education system in which students are not separated into different tracks until around the age of 16 years. Finnish educational policy makers consider that, "the single most important education policy decision taken since Finland established its independence in 1917 was to create a common, untracked comprehensive school system that would serve students from all walks of life" (OECD 2011, p.131). The introduction of a comprehensive system of education is considered by most Finnish analysts to be the foundation upon which all subsequent reforms and improved educational outcomes have rested (OECD, 2011). Careful planning meant that the implementation of change was a process that took five years to complete and was marked by ongoing consultation with teachers during the planning process as well as extensive investments in teacher training to support the new system. In addition, maintaining robust in-service training programmes to allow teachers to continually update their skills was also a key focus (European Agency for Special Needs and Inclusive Education, nd).

While Finland prides itself on its commitment to social and economic equity and to its system of comprehensive education, it is worth noting that, as is the case in Barbados, special classes within mainstream schools, as well as special schools, are also available for students with the most complex special educational needs and disabilities (OECD, 2011). Not only do such schools in Finland provide education to students with special needs but they are regarded as national development and service centres providing expertise and support services for other schools (European Agency for Special Needs and Inclusive Education, nd). While $8 \%$ of students in Finland are deemed to have special 
educational needs or disabilities, only half of these children are in special schools (OECD, 2011). So this aspect of the Barbadian education system is similar to that in Finland and need not be affected by changes to the organization of secondary schooling.

It is clear, therefore, that in order to move to a higher achieving and more inclusive and equitable education system Barbados needs to consider systemic reforms that will facilitate a move away from selective secondary schooling permeated by ability grouping, towards a more comprehensive education system.

\section{Change from Selective Secondary Education}

In order for Barbados to progress toward a more equitable and inclusive education system, with higher levels of educational achievement, there needs to be a move away from the selective secondary education that currently dominates the education scene. As emphasized by De Lisle et al. (2017), the existence of such a system of early selection and rigid academic segregation that utilizes high stakes tests, stands in contradiction to national policies in the Caribbean, including those in Barbados, that aspire to achieve an equitable education system (Ministry of Education and Human Resource Development and the Ministry of Labour, 2010). In addition, these practices are in contradiction to the central values of an inclusive education system and the goals of achieving an inclusive and equitable society (De Lisle et al., 2017; OECD, 2016). PISA results have in fact pointed to the more inclusive and equitable school systems being those that have developed comprehensive forms of education and delayed selection processes. Such systems are among the highest performing in the world, as is the case with Finland, discussed above.

Therefore, it is considered that the Barbados Ministry of Education should abandon secondary school selection by means of the CEE and introduce a zoning scheme in which all students attend the secondary school nearest to where they live, as is done in many countries with high performing education systems, such as Finland and Canada (Schleicher, 2018). This will eliminate the need for selection using the $\mathrm{CEE}$, and the hours spent travelling to school each day currently taken by the majority of secondary school students. Such a scheme has the support of many Barbadians, as illustrated by recent letters to the editor of the highest circulation national newspaper by Broomes (2018) and Harrison (2018). Broomes (2018, p.4) states,

It is nonsensical to me that at a time when we have more than enough secondary school spaces, and when there is at least one secondary school in every parish, we are still languishing in the practices that were necessary for a past that needed to function in the way to address the problems of the time, which is no longer the problem...

I see no reason why a child from St Philip should come to school in St Michael or St James. I see no reason why a child from St Lucy should come to school in St Michael or Christ Church ...

Further, Harrison (2018, p.10) suggests, "Let students go to the secondary schools closest to their homes, thus using the Common Entrance results to target those who need extra help in the classrooms."

Poder, Lauri and Veski (2017) in their study using 2009 PISA data showed that a zoning policy that allocated students places in their neighbourhood schools improved educational equity and reduced the effect of family background characteristics on academic achievement, while achievement based allocation increased inequity. However, these authors acknowledge the complexity of issues related to zoning and point out that it is not a panacea for all. There is a need for allocation policies to be sensitive to the local context. For example, a system of zoning will not necessarily be effective in countries where there are high levels of residential segregation. These authors suggest that in such situations zoning may exacerbate rather than reduce inequity. Zoning policies therefore need to be developed in such a way as to ensure that schools reflect the socio-economic, cultural and academic mix of the community, with the aim of the schooling system being to achieve a system of equivalent 
schools so that no family feels the need to travel to any school outside of their neighbourhood (Gorard and Huat See, 2013).

Because of the long tradition of selective entry in Barbados, the prestige of older secondary schools, and the uneven socio-economic distribution of the population, implementing an effective zoning system will not be easy to achieve. It is therefore proposed that one way to make the transition to a more effective, equitable and inclusive education system in Barbados would be to introduce a small number of Sixth Form Colleges. For example, the two most prestigious secondary schools, Harrison College and Queens College, could teach students in Forms One through Five and only enrol students in their Sixth Form years who are undertaking Advanced level courses. All other secondary schools would enrol students in Forms One through Five and offer Caribbean Examination Council (CXE) programmes. Students would then get into the Sixth Form Colleges based on their passes and grades in the CXE examinations taken at the end of the Fifth Form year at around 16 years of age.

All secondary schools would need to have their own geographical zones from which they draw their students. These would need to be drawn up to ensure that schools enrol similar numbers of students and that they represent as diverse a socio-economic population as possible. Teachers could remain at the secondary schools at which they had previously taught but would need to develop their teaching strategies in order to effectively deliver the curriculum to students with a broader range of abilities than they may be used to. An advantage of this approach is that schools would become more representative of their local communities, due to children attending their local schools, which would facilitate increased involvement of parents and communities, and help bring about optimal educational outcomes (Hornby, 2011).

The impact on primary school education will be an important by-product, with teachers no longer forced to concentrate most of their efforts on preparing children to sit the CEE in classes streamed for ability from as early as seven years, but instead able to deliver a broader curriculum and focus on facilitating the learning of all children, including those with special educational needs. This new system is also likely to result in increased attendance and engagement of students, who will have more energy to devote to their studies rather than being fatigued by travelling long distances to and from school. It will also be likely to result in decreased violence and delinquency in secondary age students, due to them attending schools in their local communities, with less time spent travelling on buses and waiting at bus stops with inadequate supervision. In addition, there will be positive effects on traffic and travel across Barbados due to most students no longer needing to use buses to get to and from schools, or for some parents to drive children to primary schools with good reputations for success in the CEE.

As was the case in Finland, transition to a new educational structure will need careful planning and execution. However, the potential benefits of implementing such reforms are substantial, as suggested by the impact of changes made to the Polish education system over a relatively short time frame in 1999 (Ripley, 2013). Directly following these changes Poland improved PISA reported academic outcomes by an average of three-quarters of a school year between 2000 and 2006 (Hanushek and Woessmann, 2010). Interestingly, the change made in Poland, that was considered to be mainly responsible for this improvement, was abandoning selection at entry to secondary school, thereby delaying the division of students into various streams (Jakubowski, Patrinos, Porta and Wiśniewski, 2016).

Reforming schooling systems is a challenging and politically difficult task. Such reforms take time to implement and some benefits may not be realized until student populations move into the workforce, where they can make use of their improved education, thereby furthering national economic growth (Schleicher, 2018). Therefore, it is important to also consider the longer-term impact of educational reforms, which can be substantial (Hanusheck and Woessmann, 2010). In Barbados, reforming entry to secondary schooling would not only create a much more equitable and inclusive education system, enabling the nation to raise overall academic attainment, while reducing student behavioural problems, it would also bring about the substantial long-term economic benefits that are found to result from producing a better educated population (Hanushek and Woessmann, 2010). 


\section{Conclusion}

There is a need for a change from a selective to a comprehensive secondary education system in order for Barbados to meet its goal of preparing the population for $21^{\text {st }}$ century life. This will involve abolishing selection for secondary schooling at around age 11 years and having in place school zoning that enables students to attend secondary schools nearest to their homes. The advantages of this change will be a more equitable and inclusive education system that provides high quality education for all children regardless of social class or ethnicity, and that brings about improved levels of academic achievement across the secondary school sector, with lower rates of student behavior problems, as well as the substantial long-term economic benefits of producing a better educated population.

\section{References}

Bacchus, M. K. (2006). Utilization, Misuse and Development of Human Resources in the Early West Indian Colonies. Waterloo: Wilfred Laurier University Press.

Barbados Ministry of Education (1974). Report on Transfer from Primary to Secondary Education in Barbados. Bridgetown: Ministry of Education.

Bennett, J. H. Jr. (1958). Bondsmen and Bishops: Slavery and Apprenticeship on the Codrington Plantations of Barbados, 1710-1838. Berkley: California University Press

Best, T. (2008). Achieving Excellence in Education. Barbados Union of Teachers: John Cumberbatch Memorial Lecture. Available at http://butbarbados.com/but-library.html. [Accessed 24 September 2017].

Betts, J. R. and Shkolnik, J. L. (2000). The effects of ability grouping on student achievement and resource allocation in secondary schools. Economics of Education Review, 19, pp. 1-15.

Blackman, S., Conrad, D. and Brown, L. (2012). The attitude of Barbadian and Trinidadian teachers to integration. International Journal of Special Education, 27(3), pp. 158-168.

Blouet, O. M. (1991). Earning and learning in the British West Indies: An image of freedom in the pre-emancipation decade, 1823-1833. The Historical Journal, 34(2), pp. 391-409.

Bray, M. (2013). Shadow education: Comparative perspectives on the expansion and implications of private supplementary tutoring. Procedia - Social and Behavioral Sciences, 77, pp. $412-420$.

Broomes, J. (2018). Cut down ratios in classes. Daily Nation, Monday April $16^{\text {th }}$, p. 4.

Buchmann, C., and Dalton, B. (2002). Interpersonal influences and educational aspirations in 12 countries: Importance of institutional context. Socology of Education, 75(2), pp. 99-122.

Budginaite, I., Siarova, H., Sternadel, D., Mackonyte, G. and Spurga, S. (2016). Policies and Practices for more Equality and Inclusion in and through Education: Evidence and Policy Guidance from European Research Projects Funded Under FP6 and FP7, NESETT 11 Report. Luxemburg: Publications Office of the European Union.

Carnoy, M. (1999). Globalization and Educational Reform: What Planners Need to Know. Paris: UNESCO.

Carrington, E. W. (1993). The Future of Education in the Caribbean: Report of the CARICOM Advisory Task Force on Education. St. Lucia: Caribbean Community Secretariat.

CJRPU (2017). A Profile of the Prison Population. Bridgetown: Criminal Justice Research and Planning Unit, Office of the Attorney General.

Crossley, M., Bray, M. and Packer, S. (2011). Education in Small States: Policies and Priorities. London: Commonwealth Secretariat.

Crossley, M. and Sprague, T. (2012). Learning from small states for post-2015 educational and international development. Current Issues in Comparative Education, 15(1), pp. 26-40.

Cross, M. and Schwartzbaum, A. M. (1969). Social mobility and secondary school selection in Trinidad and Tobago. Social and Economic Studies, 18(2), pp. 189-207.

De Lisle, J. (2012). Secondary school entrance examinations in the Caribbean: Legacy, policy, and evidence within an era of seamless education. Caribbean Curriculum, 19, pp. 109-143. 
De Lisle, J., Laptiste-Francis, N., McMillan-Solomon, S. and Bowrin-Williams, C. (2017). Student assessment systems in the Caribbean as an obstacle to inclusive education: The case of Trinidad and Tobago. In S. Blackman and D. Conrad (Eds.) Caribbean Discourse in Inclusive Education: Historical and Contemporary Issues. Charlotte: Information Age, pp. 87-105.

De Lisle, J., Seecharan, H. and Ayodike, T. (2010). Is the Trinidad and Tobago Education System Structured to Facilitate Optimum Human Capital Development? New Findings on the Relationship between Education Structures and Outcomes from National and International Assessments. Paper presented at the Sir Arthur Lewis Institute of Social and Economic Studies $11^{\text {th }}$ Annual Conference, Port of Spain, Republic of Trinidad and Tobago.

De Lisle, J., Smith, P., Keller, C. and Jules, V. (2012). Differential outcomes in high-stakes eleven plus testing: the role of gender, geography, and assessment design in Trinidad and Tobago. Assessment in Education: Principles, Policy \& Practice, 19(1), pp. 45-64.

Downes, A. (2003). Gender and the elementary teaching service in Barbados, 1880-1960: A reexamination of the feminization and marginalization of the black male theses. In E. Barriteau (Ed.) Confronting Power, Theorizing Gender: Interdisciplinary Perspectives in the Caribbean. Kingston, Jamaica: University of the West Indies Press, pp. 303-323.

Downes, A. (2018). Queens, Harrison, take lion's share of scholarships. Barbados: Nation News, $10^{\text {th }}$ August, p.8.

Educational Endowment Foundation (nd). The Teaching and Learning Toolkit. Available at: https:// educationendowmentfoundation.org.uk/evidence-summaries/teaching-learning-toolkit/ [Accessed 18 January 2018]

European Agency for Special Needs and Inclusive Education (nd). Finland-Special Needs Education within the Education System. Available at: https://www.european-agency.org [Accessed 16 April 2018]

Galloway, D. and Upton, G. (1990). Joint Final Report on consultancies in Special Education Needs (Secondary) and Special Education Needs (Primary) to the Ministry of Education and Culture. Bridgetown: Barbados.

Gorard, S. and Huat See, B. (2013). Overcoming Disadvantage in Education. Abingdon: Routledge.

Glossary of Education Reform. (2014). High-Stakes Tests. Available at: http://edglossary.org/highstakes-testing/ [Accessed 15 August 2017].

Hanushek, E. A. and Woessmann, L. (2005). Does Educational Tracking Affect Performance and Inequality? (Working Paper 11124). Cambridge, MA: National Bureau of Economic Research.

Hanushek, E. A. and Woessmann, L. (2010). The High Cost of Low Educational Performance: The Long-Run Economic Impact of Improving PISA Outcomes. Paris: OECD.

Harrison, D. (2018). School violence fix. Daily Nation, Monday February $12^{\text {th }}$, p. 10.

Hattie, J. (2009). Visible Learning: A Synthesis of Over 800 Meta-Analyses Relating to Achievement. London: Routledge.

Hornby, G. (2011). Parental Involvement in Childhood Education: Building Effective School-Family Partnerships. New York: Springer.

Hornby, G. and Witte, C. (2014). Ability grouping in New Zealand high schools: are practices evidencebased? Preventing School Failure, 58(2), pp. 90-95.

Hornby, G., Witte, C. and Mitchell, D. (2011). Policies and practices of ability grouping in New Zealand intermediate schools. Support for Learning, 26(3), pp. 92-96.

Jakubowski, M., Patrinos, H. M., Porta, E. E. and Wiśniewski, J. (2016). The effects of delaying tracking in secondary school: evidence from the 1999 education reform in Poland. Education Economics, 24(6), pp. 557-572.

Jamaica Task Force on Educational Reform. (2004). A Transformed Education System: Final Report. Kingston: Jamaica Task Force on Educational Reform.

Jennings, Z. (2017). Interventions in schools' curricula to achieve quality in learning: Experiences from the Commonwealth Caribbean. Compare: A Journal of Comparative and International Education, 47(6), pp. 818-834. 
Jules, V. (1994). A Study of the Secondary School Population in Trinidad and Tobago: Placement Patterns and Practices - Research Report. St. Augustine, Trinidad: Centre for Ethnic Studies, University of the West Indies.

Klenowski, V. and Wyatt-Smith, C. (2012). The impact of high stakes testing: the Australian story. Assessment in Education: Principles, Policy \& Practice, 19(1), pp. 65-79.

Kutnick, P., Sebba, J., Blatchford, P., Galton, M. and Thorp, J. (2005). The Effects of Student Grouping: Literature Review. Research Report 688. London, England: DfES.

Mayers, J. (1995). Access to secondary education for girls in Barbados, 1907-43: A preliminary analysis. In V. Shepherd, B. Brereton, and B. Bailey (Eds.) Engendering History: Caribbean Women in Historical Perspective. Kingston, Jamaica: Ian Randle, pp. 258-275.

Ministry of Education. (2008). The Development of Education: National Report of Jamaica. Jamaica: Ministry of Education.

Ministry of Education, Youth Affairs and Culture. (1995). White Paper on Education Reform: Each One Matters...Quality Education for All. Barbados: Ministry of Education, Youth Affairs and Culture.

Ministry of Education, Human Resource and Development. (2008). The Development of Education: National Report of Barbados. Barbados: Ministry of Education, Human Resource and Development.

Ministry of Education and Human Resource Development, and Ministry of Labour. (2010). Barbados Human Resource Development Strategy 2011-2016: Developing National, Institutional and Human Capacity for Sustainable Growth. Barbados: Ministry of Education and Human Resource Development, and Ministry of Labour.

Ministry of Education, Youth Affairs and Culture. (2000). Barbados Information Handbook. Barbados: Ministry of Education, Youth Affairs and Culture.

Ministry of Planning and Development. (nd). Vision 2020: Operational Plan 2007-2010. Republic of Trinidad and Tobago: Ministry of Planning and Development.

OECD (2011). Lessons from PISA for the United States: Strong Performers and Successful Reformers in Education. Paris: OECD.

OECD (2016). PISA 2015 Results (Volume II): Policies and Practices for Successful Schools. Paris: OECD.

Poder, K., Lauri, T. and Veski, A. (2017). Does school admission by zoning affect educational inequality? A study of family background effect in Estonia, Finland and Sweden. Scandinavian Journal of Educational Research, 61(6), pp. 668-688.

Ripley, A. (2013). The Smartest Kids in the World and How They Got That Way. New York: Simon and Schuster.

Rudder, R. (2014). National Education for All 2015 Review: Barbados Report. Barbados: Ministry of Education, Science, Technology and Innovation.

Schleicher, A. (2014). Equity, Excellence and Inclusiveness in Education: Policy Lessons from Around the World: International Summit on the Teaching Profession. Paris: OECD.

Schleicher, A. (2018). World Class: How to Build a $21^{\text {st }}$-Century School System, Strong Performers and Successful Reformers in Education. Paris: OECD.

Shaeffer, S. (2013). Identifying and Promoting Good Practice in Equity and Child-Friendly Education. New York: UNICEF.

Slavin, R. E. (1987). Ability grouping and student achievement in elementary schools: a best-evidence synthesis. Review of Educational Research, 57(3), pp. 347-350.

Slavin, R. E. (1990). Achievement effects of ability grouping in high schools: a best-evidence synthesis. Review of Educational Research, 60(3), pp. 471-499.

Slavin, R. E. (1993). Ability grouping in the middle grades: Achievement effects and alternatives. Elementary School Journal, 93(5), pp. 535-552.

Slavin, R. E. (1996). Education for All: Contexts of Learning. Lisse, France: Swets and Keitlinger.

Terzi, L. (2014). Reframing inclusive education: Educational equality as capability equality. Cambridge Journal of Education, 44(4), pp. 479-493. 
UNESCO. (1990). World Declaration on Education for All and Framework for Action to Meet Basic Learning Needs. Paris: UNESCO.

UNESCO. (2000). The Dakar Framework for Action, Education for All: Meeting our Collective Commitments. Paris: UNESCO.

UNESCO. (2017). A Guide for Ensuring Inclusion and Equity in Education. Paris: UNESCO.

Walker, Z. and Musti-Rao, S. (2016). Inclusion in high achieving Singapore: Challenges of building an inclusive society in policy and practice. Global Education Review, 3(3), pp. 28-42.

World Bank. (2013). How to Improve Quality of Education in the Caribbean for the Next Generation? Available at: http://www.worldbank.org/en/news/feature/2013/09/18/caribbean-qualityeducation-improvements-next-generation [Accessed 31 August 2017]. 